\title{
Les Cobles sobre Antoni Roca $(1544,1546)$ y su relación con la canción eslovaca sobre Matiáš Bazald (1549). Dos ejemplos de la literatura en servicio de la propaganda política de los Habsburgo
}

\author{
RENÁTA BOJNIČANOVÁ \\ Universidad Komenský de Bratislava
}

\section{Introducción}

La historia de Cataluña y de Eslovaquia, sobre todo durante el siglo XVI, cuando los monarcas de la casa de Austria consolidaron su poder en sus dominios hispánicos y centroeuropeos, tiene muchos puntos en común, lo que abre muchas líneas de investigación. Tanto Cataluña dentro de la monarquía hispánica como Eslovaquia en el marco del Reino de Hungría se encontraban en situación parecida, pues en ambos casos la subida al trono de los Habsburgo dio pie muchos conflictos interiores, dado que, desde el principio, tuvieron que hacer frente a la resistencia de buena parte de la nobleza autóctona, ya fuera porque deseaba conservar sus privilegios medievales, ya simplemente, como en el caso húngaro, porque se negaba a reconocer la autoridad real.

Carlos V se quejaba del caos e inseguridad que provocaban en Cataluña los enfrentamientos entre las familias nobles, sin disposición ninguna a someterse al orden que él pretendía establecer. En situación aún peor se encontraba Fernando I, quien tuvo que luchar por el trono húngaro contra el príncipe transilvano János Zápolyay y contra sus muchos partidarios en el territorio de la Alta Hungría, sin que faltaran señores feudales que aprovechaban el vacío de poder para emprender acciones armadas contra sus vecinos. En la historiografía eslovaca a estos nobles rebeldes se les conoce como «lúpežní rytieri», es decir, «caballeros salteadores», pues «lúpežník», que traduzco aquí como «salteador», en realidad es casi sinónimo de «zbojník» — «bandolero»-, si bien se trata de un vocablo que tiene algunas connotaciones diferentes. Los especialistas eslovacos llaman «zbojníci» — «bandoleros»— solamente a los forajidos procedentes de las clases populares, sin caer en la cuenta de que los «lúpežní rytieri» — «caballeros salteadores»— responden perfectamente al perfil de lo que Joan Reglà llama el «bandolerismo señorial», concepto que hasta ahora no ha sido tenido en cuenta por los historiadores eslovacos y cuyo reconocimiento y adopción por parte de éstos sería conveniente.

Llamemos como queramos a este tipo de rebeldes, los hermanos Habsburgo, Carlos I y Fernando I, consideraban sin duda que los problemas que tenían con la población autóctona de estas dos zonas de sus dominios eran muy parecidos, 
y actuaron para resolverlos de forma similar, apelando tanto al derecho, como a las armas. Carlos V desde principio de su reinado promovió varias leyes contra la criminalidad de todo tipo, pero lo que marcó la diferencia en Cataluña fue la Pragmática contra el bandolerismo catalán, firmada en Toledo en el año 1539. Al mismo tiempo dio órdenes al nuevo virrey, marqués de Lombay, para proceder duramente contra los bandidos. Los resultados de estas disposiciones no surtieron efecto de inmediato, sino que se dejaron esperar, y fue precisamente durante el mandato del siguiente virrey, Don Juan Fernández Manrique de Lara, marqués de Aguilar de Campóo y conde de Castañeda, cuando se pudieron apreciar los primeros éxitos visibles de esta política represiva, como fueron la captura de peligrosos bandidos como Moreu Cisteller en el año 1543, y de Antoni Roca en 1546.

Fernando I posiblemente se inspiró en el ejemplo de su hermano mayor cuando en el año 1549 trató en el parlamento húngaro la problemática de los «caballeros salteadores», promulgando unas leyes muy duras contra ellos, que, entre otras medidas, preveían castigarlos con una muerte humillante sin tener en cuenta su linaje, confiscar sus propiedades a favor de las arcas reales, etc. Tales leyes dieron su primer resultado sonado en aquel mismo año de 1549, con la captura de Matiáš Bazald de Čotlovo y sus compañeros, quienes se habían apoderado del castillo de Muráň y desde allí emprendían sus incursiones criminales y saqueos.

Estos dos éxitos políticos tuvieron también su reflejo en la literatura: por un lado, en las dos canciones catalanas dedicadas a Antoni Roca - Cobles novament fetes per Pere Giberga contra tots los delats de Catalunya i secaços d'Antoni Roca... (1544) ${ }^{1}$ y Cobles fetes sobre la justicia $i$ cruel mort d'Antoni Roca... (1546), y, por otro, en la canción eslovaca sobre Matiáš Bazald, Píseňo zámku Muránském (Canción sobre el castillo de Murán̆) (1549)², obra de Martin Bošňák, también conocido como Martin Vitis (Vitéz, Vitus).

\section{Paralelismos entre les Cobles y la Canción sobre el castillo de Murán̆}

Hasta ahora nadie se había dado cuenta de la relación que existe entre estas tres canciones, por una simple razón: no había conciencia sobre su paralelismo

\footnotetext{
${ }^{1}$ Los títulos completos de estas canciones son, respectivamente: Cobles novament fetes per Pere Giberga contra tots los delats de Catalunya i secaços d'Antoni Roca, recordant-los la cruel sentència i mort del Galipapo i altres dos de lur companyia, la cual passarà per tots ells si no buiden prest a terra. Any MDXLIV y Cobles fetes sobre la justícia i cruel mort d'Antoni Roca, escandalitzador de tota Catalunya, i de Sebastià Corts, son companyó. La segunda canción es anónima, pero es muy probable que su autor sea igualmente Pere Giberga. Fueron reproducidas por Marià Aguilò en su Cançoner de les obretes en nostra lengua materna més divulgades durant los segles XIV, XV i XVI, Barcelona, 1873-1900.

${ }^{2}$ La canción está conservada en el Museo nacional eslovaco, en el manuscrito número 545, copiada por Imrich Lauček probablemente en el año 1834 e impresa en Národné spievanky [Canciones nacionales] de Ján Kollár en 1835. La fuente directa de Lauček y Kollár fue la antología manuscrita de canciones históricas de Matej Holka, recopilada entre los años 1756 a 1789.
} 
temático. Los especialistas catalanes consideran las dos composiciones sobre Antoni Roca como las canciones catalanas de bandidos más antiguas (Gibert, 1989: 24), testimonios valiosos de la existencia del bandolerismo durante la época en la que éste «tenía un reflejo muy pálido» en la literatura (Comas, 1985: 371). Por su parte, la Canción sobre el castillo de Muráň está considerada por los estudiosos eslovacos como la canción histórica ${ }^{3}$ más antigua (Minárik, 1982: 12). Dentro de las canciones históricas tiene un lugar especial, no sólo por ser la más antigua, sino porque temáticamente no se ajusta al perfil de la mayoría de las canciones históricas, ya que éstas tratan en su mayoría del tema de la lucha antiturca, o bien de la temática contra los Habsburgo, al narrar los malos tratos que los ejércitos imperiales infligían a la población autóctona. Por tanto, podemos decir que tanto Les Cobles como la Canción sobre el castillo de Muráň se consideran un elemento «anómalo» dentro de su contexto literario. Otra cosa que tienen en común es que, siendo las primeras de su género, marcan el principio de un estilo nuevo de canciones que se iba a generar según su modelo en las dos literaturas. Les Cobles sirven de modelo para las posteriores canciones de amenaza y advertencia contra los bandoleros ${ }^{4}$, en tanto que la Canción sobre el castillo de Muráň es la primera de una serie de canciones que comentan los hechos político-bélicos de su tiempo, como son las conquistas de castillos, los asaltos de los turcos, etc.

Estas tres canciones «anómalas», o bien se pueden estudiar dentro de su contexto literario propio, labor muy importante de la que ya se ocuparon los historiadores literarios catalanes y eslovacos, o bien, lo que propongo en este artículo, se pueden situar en el contexto europeo común y ser valoradas desde esta perspectiva exterior. En este caso abrimos posibilidades de llevar a cabo una interesante comparación catalano-eslovaca.

Puede ocurrir, si analizamos estas obras, que a primera vista no encontremos ningún punto común que diera pie a tal comparación. Esto es porque las coincidencias no se basan en un parecido superficial, sino que están relacionadas con el trasfondo político de su creación y con las circunstancias en las que se compusieron.

En primer lugar, lo más obvio que se puede constatar respecto a ellas, es que son prácticamente coetáneas. Hay sólo tres años de diferencia en cuanto a la fecha de aparición de les Cobles de Pere Giberga y de la Canción sobre el castillo de Muráň. Al mismo tiempo, las tres canciones comparadas, como ya he sugerido, tienen antecedentes muy semejantes, es decir, un hecho histórico similar que les sirvió de inspiración. Se trata de la captura y el castigo de unos criminales peligrosos: en Cataluña, de un tal Galipapo y dos de sus hombres (primera Cobla) y de Antoni Roca y Sebastià Corts, su compañero (segunda Cobla), y

${ }^{3}$ Las canciones históricas (historické piesne) son un género poético semipopular de los siglos XVI y XVII, que se inspiran generalmente en temática antiturca y antihabsburga y expresan el patriotismo humanista del Reino de Hungría (Minárik, 1982: 9).

${ }^{4}$ Por ejemplo, las canciones dedicadas a la captura y muerte de los bandoleros Trucafort y Tallaferro: Cobles de Trucafort $i$ Tallaferro i del bon govern del duc d'Alburquerque, ab un soneto a la fi, 1616, de Tocasson, Coplas de la presa de Tocasson, cap de quadrilla, 1631. 
en Eslovaquia de Matiáš Bazald y los suyos, es decir, sus hermanos, sus hijos y el burgrave del castillo de Muráň, llamado Ferenc. ¿Quiénes eran estos personajes?

Antoni Roca fue un célebre bandolero catalán, cuya fama se consolidó gracias, sobre todo, a una obra que Lope de Vega escribió sobre él. Galipapo fue otro bandido capturado dos años antes que Roca, y Matiáš Bazald fue uno de los más conocidos «caballeros salteadores», sobre los que ya se ha hablado anteriormente. Tal como narran las canciones, la actividad de Galipapo, Antoni Roca y los demás bandidos catalanes (se menciona a Pujades, Semenat y Sebastià Corts) y la de Matiáš Bazald era similar. Les Cobles hablan de asesinatos, robos, sacrilegios, traiciones, tal como queda claro de los siguientes versos:

\author{
Guardau que criden justícia \\ davant Déu los que matàreu \\ y molts altres que robàreu \\ descobrint vostra malícia... \\ Quius veya fer sacrilegis, \\ robos y traycions devia \\ lora y el jorn queus acollia \\ perdre tots lurs privilegis.
}

(Gibert, 1989: 25)

y en la Canción sobre el castillo de Muráň se comenta sobre asaltos, asesinatos, secuestros y robos:

Radu sou tam, jednání mívali $v$ horách mnohé lidi loupili, mordovali, také zabíjeli a na Murán zajímané často vodili. Také loupežství mnohé činili pánůn i zemanům, nevolné bili, žádného jsou oni nelitovali, Voly, kravy zajímali, na Muráň honili.
Allí tenían sus reuniones, y en los montes asaltaban la gente $l a$ asesinaban, la mataban, y llevaban prisionera a Murán̆. También hacían otros asaltos, oprimían a señores e hidalgos, no tenían piedad de nadie, robaban vacas y bueyes, $y$ se los llevaban a Muráñ.

(Minárik, 1982: 70)

No hay duda, por tanto, que en el caso de la Canción sobre el castillo de Murán̆ también se trata de una canción de bandidos ${ }^{5}$, aunque en la Historia de la Li-

${ }^{5}$ Es posible que lo que pudo inducir a que la Canción sobre el castillo de Muráň pasara desapercibida a los estudiosos interesados en el bandolerismo, es que Bazald y sus hombres en ningún lugar del texto son llamados directamente «zbojníci» — «bandidos»—, sino que, para referirse a ellos, se utilizan otras expresiones, como pueden ser «turbáky»— «perturbadores»—, «loupežníky»—《asaltadores»—, «mordárì — «asesinos»—, «zli škodníky», «záškodníky»—《malhechores»—, etc. Sin embargo, ocurre lo mismo con Les Cobles, en las que a Galipapo, a Antoni 
teratura Eslovaca tradicionalmente no le haya atribuido tal condición ${ }^{6}$. De modo que tenemos el primer punto común entre ésta y les Cobles, y es su clasificación temática, según la cual, además, la Canción sobre el castillo de Muráň se colocaría en un lugar especial, y es que no sólo es la más antigua canción histórica, sino también, igualmente que Les Cobles, la más antigua canción de bandidos eslovaca, de modo que comparamos dos obras equivalentes: los primeros testimonios literarios sobre el bandolerismo en Cataluña y Eslovaquia.

Aunque las canciones catalanas y la eslovaca tienen el tema común, éste está tratado de manera diferente. Si comparamos los elementos constructivos de su composición, en principio son idénticos: descripción de los delitos de los bandidos, referencia a la represión contra ellos llevada a cabo por parte de las autoridades reales, y la condena y el justo castigo dado a los delincuentes. Sobre esta estructura básica están sobrepuestos elementos particulares que hacen diferente a cada canción. En el caso de las dos canciones catalanas, los autores (o el autor) centran su atención en el momento de la humillación pública y ejecución, que se describe con detalle, un episodio de la cual es la tortura con las tenazas:

Ab tenalles foguejants
el botxí lo festejaba
y ab aquests jochs semejants
per les carreres anava
ab aquell companyo seu
Corts que detràs lo seguia
rossegant amb gran menyspreu
no encara com devia.

(Gibert, 1989: 32)

Por el contrario, la Canción sobre el castillo de Murán̆ tiene por objetivo describir detalladamente todo el procedimiento de la captura de los bandidos (es decir, los asaltos al castillo en el que habían refugiado, la fuga de Matiáš Bazald y su captura por parte del alcalde de Telgárt), mientras que al cumplimiento de la justicia se dedican tan sólo dos versos:

\footnotetext{
Roca, etc., en vez de llamarlos «bandolers», el autor les llama con otras denominaciones despectivas sinonímicas, como son malfactors, homs matadors i ladres, mals homens, traydós lladres y omicides (primera Cobla), adelats, lladros, malvats, matadors, traydors (segunda Cobla). Además, sinceramente creo que no es necesario que en el texto de la canción aparezca directamente el vocablo «bandido», pues se trata que de esta clase de criminales se infiere de la descripción de su actividad.

${ }^{6}$ Esta canción ha pasado desapercibida a los estudiosos interesados en el bandolerismo, simplemente porque el «bandolerismo señorial» hasta ahora no había sido contemplado como tal en la historiografía eslovaca, y a los nobles bandoleros, conocidos como «caballeros salteadores», se les considera sólo como practicantes de una criminalidad feudal, distinta de la de los «bandidos» de origen plebeyo. El puesto de las más antiguas canciones de bandidos, por tanto, se atribuye tradicionalmente a las composiciones sobre Adam e Ilčík, sobre Jakub Surovec y sobre Jánošík, todas de mediados del siglo XVIII.
} 
$V$ trech dnech dal gróf všeckých stínati, tak byl od veznů plač veliký.

(Minárik, 1982: 75)

En los tres días siguientes el conde mandó decapitarlos a todos, y los prisioneros lloraron mucho.

Finalmente, en las tres canciones encontramos a los bandidos vencidos, castigados y humillados, lo que da motivo al autor para expresar su alegría (Martin Bošňák), y en el caso catalán, también la esperanza de que se iniciarán tiempos de tranquilidad y seguridad.

El punto común más importante entre las tres canciones es, sin embargo, su funcionalidad, y la primera entre sus funciones es la informativa. El objetivo principal de todas estas obras es hacer saber al mayor público posible que los temidos enemigos del orden público han sido vencidos y que el país está gobernado con mano firme. En esa época, cierto tipo de canciones tenía como principal objetivo el transmitir información, siendo, por tanto, como una especie de género periodístico. Estas canciones eran interpretadas en sitios públicos por cantantes vagabundos, quienes vivían de los donativos del público oyente. Les Cobles, además, circularon desde el principio también en forma de pliegos sueltos, pues los textos de estas canciones muchas veces se imprimían y vendían en las ferias, cerca de las iglesias, en plazas públicas, etc., en tenderetes improvisados, donde tales pliegos se exhibían sujetos con pinzas a una cuerda tendida, por lo que más tarde se les dio el nombre de «canciones de cordel» («cançons de fil i canya» en catalán). En Eslovaquia, el uso de la imprenta se generalizó más tarde, aunque parece que ya en el siglo XVI se conocían los pliegos sueltos (Šmatlák, 1997: 191). Sin embargo, no hay constancia de que la Canción sobre el castillo de Muráň se divulgara impresa, sino que se conservó gracias a la tradición oral y a las copias manuscritas del texto, y por lo visto era bien conocida, porque el célebre poeta Ján Silván (1493-1573) cita varias veces su melodía en su famosa antología de canciones y salmos (1571). Se trata de una típica canción de función informativa, transmisora de un claro mensaje amenazador para unos y tranquilizador para otros. Hasta podríamos decir que esta canción se rige según algunas normas del estilo periodístico actual, por el modo tan pormenorizado de la narración, la aportación de datos concretos, nombres y lugares, así como la fidelidad y fiabilidad de lo relatado, dado que su autor se proclama testigo ocular de los hechos.

En les Cobles, a la función informativa se suma, hasta podemos decir que se sobrepone, una clara función exhortativa y moralizadora. La exhortación va dirigida, en primer lugar, a los bandidos y, en segundo, a sus simpatizantes y encubridores, lo que deja adivinar lo amplio de las bases de apoyo con las que contaban los bandidos en esta época: campesinos, religiosos y familias nobles, que les proporcionaban refugio en sus masías, monasterios y castillos. La advertencia tiene forma de una amenaza directa, recordando a los bandidos el mal fin de sus compañeros capturados, cuyos cuerpos descuartizados eran colocados, para 
escarmiento general, en la calle de Regomir, una de las principales vías urbanas de la Barcelona medieval:

Malfactors, buydau la terra, no us vullau detenir.

Guardau-vos de la desferra

del carrer de Regomir.

(Gibert, 1989: 24) (primera Cobla)

También se recordaba la cruel ejecución de su capitán:

\author{
Recort vos desta jornada \\ adelats pus a vos toca \\ veent ques ya acabada \\ la vida d'Antoni Roca.
}

(Gibert, 1989: 31) (segunda Cobla)

La primera de les Cobles está directamente dirigida a Antoni Roca, que por aquel entonces se había refugiado en Francia, y también se mencionan los hombres de Pujades y de Semenat. La segunda Cobla está dirigida a los compañeros y los simpatizantes de Antoni Roca. En su mensaje amenazador, Les Cobles apelan en primer lugar a las emociones. Se estimulan los sentimientos de terror al describir los cuerpos descuartizados de los ajusticiados (primera Cobla), o las torturas y humillaciones públicas de los condenados (segunda Cobla); y los sentimientos de compasión, por ejemplo, en la conmovedora escena de la visita de la madre de Antoni Roca a la cárcel (segunda Cobla). Es curioso hacer notar que posteriormente este motivo pasó de Les Cobles a las canciones populares sobre bandidos, por ejemplo en El pres de Perpinyà (Gibert, 1989: 91).

Por otro lado, se apela también a la razón y la conciencia, lo que se hace a través de las explicaciones de lo justo y adecuado del castigo. En Les Cobles de Pere Giberga se hace una reflexión al respecto, basándose en citas las evangélicas y jurídicas. Por ejemplo:

Quel home que matara
a nengun altra persona
lo semblant dell se fara
diu esta ley sancta y bona.
La ley primera Yn vijs
difestis ad legem (parla)
corneliam de sicarios
y és rahó de venerarla.

(Gibert, 1989: 33)

Curiosamente, el mismo procedimiento encontramos en Canción sobre el castillo de Murán̆, donde se pone de ejemplo una cita del Antiguo Testamento: 
V̌̌ak to píše Iziáš prorok

$v$ tretím a tridsátém svém položení:

«Ach, člověče hříšný, proč tak loupíš?

Však i sám tak potom loupen budešs!»

(Minárik, 1982: 71)

El profeta Isaías escribe

en su capitulo treinta y tres:

«Ay, pecador, ¿por qué asaltas?

¿Luego a ti te asaltarán!»

El autor de las canciones catalanas obviamente era culto y conocía no sólo las Sagradas Escrituras, sino también las leyes promovidas recientemente por Carlos I. Por ejemplo, en ciertos pasajes de Les Cobles podemos encontrar versificados algunos párrafos de la Pragmática contra los bandidos catalanes, que prescribían que hay que castigar sin piedad a los simpatizantes de bandoleros aunque sean del estamento noble:

quius honrava y nous desterra

tenallat mereix morir.

(Gibert, 1989: 25) (primera Cobla)

o que los nobles que apoyan a los bandidos deben de perder sus privilegios:

Quius veya fer sacrilegis,

robos y traycions devia

lora y el jorn queus acollia

perdre tots lurs privilegis.

(Gibert, 1989: 25) (primera Cobla)

o incluso se utiliza le lema de « Via fora!», con el que la población tenía obligación de avisar, si viera algún grupo de hombres armados sospechoso:

Via fora, y vagen fora

causadors dinfinir mal,

via fors sacramental!

(Gibert, 1989: 26) (primera Cobla)

Igualmente, Canción sobre el castillo de Murán̆ contiene normas del decreto de Fernando I contra los caballeros salteadores, pero se les dedica mucha menos atención, pues sólo en una estrofa se comenta que el rey mandó conquistar el castillo y no tener ninguna piedad de Bazald, y esta ley fue obedecida, porque cuando Bazald pide la clemencia, no se le perdona.

El castigo de los bandidos es duro, pero es lo que dicta la ley, y ésta es justa y dada por Dios. Su pena está explicada en los dos casos, catalán y eslovaco, 
como castigo divino. Igualmente se explica que la ayuda contra los bandidos ha venido del mismo Dios, quien oyó súplicas de los dañados, como leemos en estas estrofas:

Mirau ques igual sentència
per matar-vos ordenada
y és del cel crech devallada
per los crims de resistencia.
Guardau que criden justícia
davant Déu los que matàreu
y moltes altres que robàreu
descobrint vostra malícia...

(Gibert, 1989: 25) (primera Cobla)

Igual explicación aparece en la Canción sobre el castillo de Murán̆, es decir, que la ayuda vino de Dios y, por tanto, el castigo recibido por los malhechores es un castigo divino:

Jezu Kriste, Pane milostivý!

Krik, plač, kvílení nebohých lidí, verné volání od svých ovcí uslýšel je Pán Bůh ve dne i v noci.

Nezapoměl Pán Bůh všemohoucí, aby nedal z nebe žádné pomoci loupežníky, mordářů trestati a tudy své věrné $k$ své sláve prijíti.
¡Jesucristo, Señor misericordioso!

Gritos, lamentos de la gente matada, súplicas de sus ovejas, oía el Señor día y noche.

El Señor Todopoderoso no se olvidó, mandó del cielo la ayuda hizo castigar a los asaltadores, y a sus fieles los condujo a la gloria.

(Minárik, 1982: 71)

Además, de todas estas funciones, la informativa, la exhortativa y la moralizadora, las tres canciones tienen un perfil panegírico. Esta faceta prevalece claramente en Les Cobles, en las que a los vencedores de los bandidos y protectores del orden público se les dedican unos versos de verdadero encomio. Tanto el rey como el virrey marqués de Aguilar son objeto de alabanza en la primera de Les Cobles:

Viscal Rey quen nostra terra

tal President féu venir, quels delats axils desterra quan mal horals cal fugir.

(Gibert, 1989: 26) (primera Cobla)

La apología del virrey es aún más patente en la segunda Cobla:

Viscam tots sense pesar ab gran descans y plahers. Pus lo Marquès Daguilar ha fet fi dels bandolers. 


\section{(Gibert, 1989: 34)}

En Canción sobre el castillo de Muráň, el elogio a las autoridades está expresado más sutilmente, pero se sobreentiende que los vencedores de los bandidos están del lado del bien y merecen un gran agradecimiento. Se menciona concretamente al rey Fernando, poderoso y justo, al capitán conde Nicolás de Salm (hejtman gróf Mikuláš z mesta Salma), quien dirigió la acción bélica, a los hombres del rey (lid královský), a los colaboradores de los hombres del rey, concretamente al consejero real y al gobernador del castillo de Šráriš Jiř́k Vernerius, a un fiel soldado llamado Ferenc Bebek, a los heroicos mercenarios españoles (Španělé hrdinskí) (se recuerda que eran tres mil, muy valientes, y tiradores con buena puntería), y a los corchetes húngaros (uhorští drábi). El panegírico dedicado a ellos no es, como ya he escrito, tan directo, pero está implícito en los epítetos y en la manera de describir sus actitudes.

Finalmente, las tres canciones tienen cierto sabor a manipulación de la opinión pública. Se transmite a la población un mensaje tranquilizador acerca del restablecimiento de la seguridad y se la convence de que las autoridades tienen mano dura y controlan perfectamente la situación. Por ejemplo, Fernando I ya ha conquistado los castillos de Gýmeš, Hrušov, etc., que eran «desobedientes al rey» («kteríž králi nebyli poslušní»), de modo que sus adversarios tienen que quedar desmoralizados:

Neb se zajisté žáden nezkryje,

na kohokoli Pán Bůh svou moc pošle,

na Hrušov, Sitnu i na Levice,

Čabrag zámek i Muráň král má v své moci.

(Minárik, 1982: 72)

Porque ciertamente nadie escapa
de aquellos contra los que el Señor hace sentir su fuerza.
Los castillos Hrušov, Sitna y Levice,
Čabrag y Muráň el rey ya tiene en su poder.

El autor catalán proclama con entusiasmo que gracias al marqués de Aguilar, el bandolerismo ha acabado de raíz:

Aquel que escandalitzava

Cathalunya y Ruysselló

el Marquès lo aguaytava

per posar lo al pavelló,

tant ha fet ab son valor

per guardar nos de desplers.

La Marquès gran Daguilar

ha fet fi dels bandolers.

(Gibert, 1989: 34) 


\section{Las principales diferencias entre Les Cobles y La canción sobre el castillo de Muráň}

Hasta aquí los paralelismos entre las más antiguas canciones de bandoleros catalanas y la eslovaca. ¿Cómo se pueden resumir sus principales diferencias?

Las diferencias, dejando aparte, claro está, circunstancias tan obvias como la etnia y la lengua de los autores, radican precisamente en los recursos estilísticos empleados en cada caso y en la manera de enfocar la promoción y divulgación de estas obras. Como ya se ha apuntado, la finalidad de estas canciones era, en primer lugar, la de intentar llegar a un público lo más amplio posible, por lo que el estilo de dichas canciones buscó aproximarse al gusto de las masas. Los autores aprovecharon e imitaron el estilo popular, hecho que constatan tanto los especialistas catalanes (Comas, 1985: 373) y los eslovacos (Šmatlák, 1997: 191). En el caso catalán, por mucho que se introdujeran pasajes de apariencia culta y distinguida (fórmulas jurídicas y morales), se nota claramente la aproximación al tipo de poesía «de fil y canya», acorde con las preferencias del populacho, de modo que de allí tenemos explicado el tremendismo y la morbosidad de algunas escenas. Los versos de tipo «sang i fetge», como es conocido, satisfacían la curiosidad malsana del público vulgar. La influencia de este tipo de producción es muy patente también en algunos géneros de la canción popular catalana, muy en particular de las llamadas «cançons de bandolers i lladres del camí ral».

En el caso eslovaco, los elementos de la canción popular en la Canción sobre el castillo de Muráň se hacen patentes de una manera diferente y más artística. La influencia de las canciones de cordel en la producción popular es mucho más tardía, de modo que si la canción popular pudo influir en algo, no fue en la vulgaridad, sino en la sutileza: los epítetos estereotipados, la gradación, discurso directo de algunos personajes, de sus imágenes, como, por ejemplo, la preciosa imagen poética al principio de la canción del blanco castillo que brilla en la alta roca, es típica de las canciones folclóricas. Todo lo contrario, se huye de las imágenes tremendistas, por ejemplo, la tortura del criminal está sólo sugerida, no descrita:

Ó, ty neverný šoltýs terkartský,
nemels' nad Bazaldem žádné lítosti!
Zvázal si jemu ruce i nohy,
mél jest Bazald od tebe velké muky.

(Minárik, 1982: 74)

Oh tú, impío alcalde de Telgárt, no tuviste ninguna lástima de Bazald.

Le ataste de pies y manos

Bazald sufrió grandes tormentos de ti.

Otra diferencia que salta a la vista entre las canciones catalanas y la eslovaca está relacionada con el destinatario de las canciones, cosa que ya se ha dicho. Por supuesto, las tres están dirigidas a la población en general, pero Les Cobles, 
sobre todo, a los bandidos y a sus simpatizantes. De allí los elementos de estilo retórico, como las alocuciones directas, exclamaciones, etc., rasgos propios de una arenga política.

Y otra diferencia más, muy fundamental, entre las canciones catalanas y la eslovaca, esta vez respecto a sus personajes principales. Aunque Antoni Roca y Matiáš Bazald sean del mismo "gremio», está claro que no representan exactamente el mismo tipo de bandido. Indudablemente, Matiáš Bazald era un poderoso señor feudal que residía en un castillo y desde allí emprendía sus incursiones criminales, tal como responde al perfil de un típico «bandido señorial». Es posible que el reverendo Antoni Roca también fuera de origen noble, pero de la baja nobleza, y evidentemente, su estilo de bandidaje era diferente. Estaba en perpetuo movimiento, iba con su cuadrilla de un sitio para otro, también se refugiaba en los castillos, pero no para apoderarse de ellos, sino acogido por sus simpatizantes. Por tanto, su captura seguramente tuvo que llevarse a cabo por otro procedimiento y no se pareció en nada a una campaña militar de asalto a una fortaleza. De allí seguramente viene la diferencia relacionada con el enfoque de los hechos en las tres canciones comparadas: junto a la solemnidad que merece una campaña militar, donde brilló la heroicidad de los soldados reales y el buen juicio de las autoridades, la ejecución de los delincuentes no tenía tanto interés, como es el caso de la Canción sobre el castillo de Muráň. En cambio, la captura, seguramente mucho menos arriesgada, de Galipapo y de Antoni Roca en campo abierto no suscitaría tanto interés e impresionaría mucho menos que el relato de una aparatosa ejecución celebrada con toda solemnidad en Barcelona.

Una curiosidad al margen: Cuando los hombres del virrey iban tras Semenat y Pujades, también era objetivo de persecución el señor de Arsèguel, Janot Cadell, quien, según Carlos I «tenía toda aquella tierra de Cerdaña sin libertad ni justicia» (Reglà, 1962: 41). Janot Cadell vivía en un castillo, tenía una cuadrilla (más bien un ejército particular), etc.: en suma, se parecía mucho a Matiáš Bazald. Fue el propio rey Carlos I, quien en una carta fechada el 2 de octubre de 1539, mandó al virrey apresarlo, y pidió la colaboración también al rey de Francia. Es posible que para prender a Janot Cadell hubiera que conquistar también un castillo. Sería interesante saberlo y buscar en algún rincón de archivos o de bibliotecas si hay alguna canción sobre la captura de este bandido, o de algún otro bandolero «señorial», de los muchos, de los que mencionan los historiadores, tal como Joan Fuster (1963: 30) sugiere cuando escribe que algunas de estas coplas «potser s'han perdut o resten en algun racó inexplorat de biblioteca».

Por último, tal como ha quedado patente, las canciones catalanas tenían por objetivo sobre todo advertir y amenazar (por eso los motivos tan tremendistas), en tanto que la canción eslovaca, con su estilo más solemne, pretendía, más que otra cosa, guardar memoria de la hazaña de los vencedores. Sin duda, también es evidente que Martin Bošňák (Bosnyák) tenía presentes los criterios estéticos en más medida que el autor catalán, para quien lo más importante era impactar. 


\section{Conclusión}

Lo que tienen en común las tres canciones es que son un claro ejemplo de poesía propagandística y política. Además de la justificación del castigo de los malos y la alabanza de los vencedores, las tres pretendían ganarse la opinión pública y convencer a los oyentes de lo justo de las duras represalias dirigidas por los reyes Habsburgo, Carlos I en España y Fernando I en Hungría, contra sus adversarios. En los tres casos también es cierto que estas canciones no son fruto de una inspiración espontánea, sino que están compuestas por encargo. Precisamente gracias a ello conocemos el nombre de los autores. Por tanto, en los dos casos, el catalán y el eslovaco, tenemos delante un ejemplo de literatura «oficial», un ejemplo de cómo la literatura, y en el caso catalán la imprenta también, fue aprovechada por los poderosos para influir sobre la opinión pública y hacer notar su poder.

En definitiva, creo que el haber enmarcado las canciones más antiguas de bandoleros en la literatura catalana y en la literatura eslovaca dentro de un más amplio contexto europeo ha proyectado una nueva luz sobre su clasificación y valoración. La comparación y la perspectiva de verlas desde fuera pueden ayudar a entenderlas mejor. Les Cobles, viéndolas así, no son sólo las canciones catalanas de bandidos más antiguas, y la Canción sobre el castillo de Muráň no es sólo una extraña canción histórica, sino que las tres, además de todo esto, son buenos ejemplos de literatura oficial al servicio de las propaganda política y acaso también precursoras de lo que podríamos llamar la «línea oficialista del periodismo». De este modo, no son tan anómalas ni están tan aisladas en las dos literaturas que hemos comparado, sino que están vinculadas entre sí, siendo un testimonio del bandolerismo señorial del siglo XVI en dos zonas en las que los Habsburgo necesitaban consolidar su poder.

Es muy interesante que se haya dado esta coincidencia en cuanto al inicio de la temática de bandidos en la literatura catalana y eslovaca, pero teniendo en cuenta la similitud de las circunstancias históricas, esto no puede sorprender. Como ya quedó demostrado, el bandolerismo en estas dos zonas es comparable en muchos sentidos y por ello era lógico que una situación histórica paralela se reflejara de manera parecida también en la literatura.

\section{BIBLIOGRAFÍA}

BoJNIČANOVÁ, Renáta (2008): La figura del bandolero en la literatura oral eslovaca y catalana. Paralelos folclórico-literarios. Colección digital de tesis de la UCM.

ButiÑÁ JiMÉNEZ, Julia (coordinadora) (1998): Literatura catalana II. Siglos XVI-XIX. Universidad Nacional de Educación a Distancia. Madrid.

Comas, Antoni (1985): Història de la literatura catalana. Volum V. (Coord. Martí de Riquer) Editorial Ariel, S. A., Barcelona.

FUSTER, Joan (1963): El bandolerisme català II. La llegenda. Aymà. Barcelona.

GiBert, Josep (1989): Cançons de bandolers i lladres de camí ral. Edicions Raima. Moià. 
KovÁČ, Dušan a kolektív (1998): Kronika Slovenska. Od najstarších čias do konca 19. storočia. Fortuna Print. Bratislava.

Mestre i CAmpI, Jesús, dir. (1993): Diccionari d'història de Catalunya. Edicions 62. Barcelona.

MINÁRIK, Jozef (1982): Slovenská renesančná lutna. Antológia zo slovenskej renesančnej poézie. Tatran. Bratislava.

MINÁRIK, Jozef (1997b): Z klenotnice staršieho slovenského písomníctva. II. Renesancia a Humanizmus. Slovenský Tatran. Bratislava.

MišIANIK, Ján (1964): Antológia staršej slovenskej literatúry. Vydavatel'stvo SAV. Bratislava.

REGLÀ, Joan (1962): El bandolerisme català I. La història. Aymà. Barcelona.

REGLÀ, Joan (1987): Els virreis de Catalunya. Ediciones Vicens-Vives. Barcelona.

ŠMATLÁK, Stanislav (1997): Dejiny slovenskej literatúry I. (9.-18. storočie). Národné literárne centrum. Bratislava.

VILIKOVSKÝ Jan (1935): «Tři nejstarší slovenské zbojnické písně». In: Bratislava 9, págs. 550-573. 